\title{
Wettability of chalk and argillaceous sandstones assessed from T1/T2 ratio
}

\author{
Katika, Konstantina; Saidian, Milad; Fabricius, Ida Lykke
}

Publication date:

2016

Document Version

Publisher's PDF, also known as Version of record

Link back to DTU Orbit

Citation (APA):

Katika, K., Saidian, M., \& Fabricius, I. L. (2016). Wettability of chalk and argillaceous sandstones assessed from $T_{1} / T_{2}$ ratio. Paper presented at 78th EAGE Conference \& Exhibition 2016, Vienna, Austria.

\section{General rights}

Copyright and moral rights for the publications made accessible in the public portal are retained by the authors and/or other copyright owners and it is a condition of accessing publications that users recognise and abide by the legal requirements associated with these rights.

- Users may download and print one copy of any publication from the public portal for the purpose of private study or research.

- You may not further distribute the material or use it for any profit-making activity or commercial gain

- You may freely distribute the URL identifying the publication in the public portal

If you believe that this document breaches copyright please contact us providing details, and we will remove access to the work immediately and investigate your claim. 
Wettability of chalk and argillaceous sandstones assessed from $T_{1} / T_{2}$ ratio

Konstantina Katika ${ }^{1}$, Milad Saidian ${ }^{2}$, Ida L. Fabricius ${ }^{1}$

${ }^{1}$ Technical University of Denmark, ${ }^{2}$ Colorado School of Mines

\section{Summary}

Low field nuclear magnetic resonance (NMR) relaxation of the fluids inside the porous rock is the result of bulk and surface relaxation of the protons inside the pore fluid. Bulk relaxation is a fluid property when the solid-fluid interaction is minimized; and surface relaxation is the result of the solidfluid interaction and is related to the mineral properties. Thus, longitudinal, $T_{1}$, and transverse, $T_{2}$, relaxation times should in principle be similar. However, microscopic magnetic gradients related to minerals can shorten $T_{2}$ relaxation times as compared to $T_{1}$ relaxation times provided the saturating fluid has high affinity to the solid. We consequently find that the $T_{1} / T_{2}$ ratio can quantify the affinity between the rock and wetting pore fluid. The affinity is a measure directly linked to wettability.

In order to investigate the $T_{2}$-shortening, we performed $T_{1}$ - $T_{2}$ maps NMR experiments on different samples of chalk, Berea sandstone, and chloritic greensand, saturated either with water, oil or oil/water at irreducible water saturation. The $T_{1} / T_{2}$ ratio obtained from $T_{1}-T_{2}$ maps reflects the $T_{2}$ shortening, so we compare the $T_{1} / T_{2}$ ratio for the same type of rock, saturated with different fluids. The chalk shows high affinity for water, Berea sandstone has no clear preference for oil and water whereas chloritic greensand shows different behaviour for small and large pores as defined in the MICP throat size distribution. Small pores (fast relaxing components) have $\left(T_{1} / T_{2}=2.0\right)$ when water saturated, but $\left(T_{1} / T_{2}=3.8\right)$ when oil saturated indicating oil-affinity. By contrast large pores (slow relaxing components) have significant preference for water $\left(T_{1} / T_{2}=2.2\right)$ as compared to oil $\left(T_{1} / T_{2}=1.2-1.4\right)$. 


\section{Introduction}

Defining the wettability of a hydrocarbon reservoir is one of the major challenges in reservoir evaluation. The wettability of reservoir rocks affects the distribution of oil and water and the residual saturations of reservoir fluids. It also influences the amount of oil that is ultimately recoverable as well as the rate at which the oil is recovered (Freedman et al., 2003). Low field NMR spectrometry is a non-destructive technique that provides information about the pore structure, the amount and type of pore fluids and the solid-fluid interaction. Therefore, the wettability of a formation can be determined by the relaxation of the protons of the fluid that adsorb to the grain surface; when the fluid interacts with the solid (Howard, 1998).

There are two types of proton relaxation associated with low field NMR spectrometry: longitudinal and transverse relaxation (Dunn et al., 2002). Longitudinal and transverse proton relaxation of fluid in a porous medium may both contain an element of bulk relaxation; when the interaction of the fluid with the solid is small, but they are typically dominated by surface relaxation; where limited pore size and molecular diffusion cause the majority of molecules to take part in solid-fluid interaction. In a uniform magnetic field, bulk and surface relaxation rates are similar for both longitudinal and transverse relaxation, but a third relaxation mechanism, that affects the transverse more than the longitudinal relaxation, is caused by molecular diffusion in a macroscopic or microscopic magnetic field gradient (Dunn et al., 2002). Assuming that the bulk fluid relaxation is slow compared to surface relaxation and that the relaxation due to field gradients is negligible, the longitudinal or transverse relaxation rates are similar, $1 / T_{1,2},(1 / \mathrm{s})$ and proportional to the surface-to-volume ratio, $S / V,(1 / \mu \mathrm{m})$ of the pore space.

$$
\frac{1}{T_{1,2}}=\rho_{1,2} \frac{S}{V}
$$

The surface relaxivity, $\rho_{1,2}$, quantifies the ability of a mineral to enhance relaxation and is considered to be constant for any given solid-fluid system (Keating and Knight, 2012).

Several authors claim that $T_{1}$ (longitudinal relaxation time) and $T_{2}$ (transverse relaxation time) may be used to define the wettability of a formation (Hsu et al., 1992; Howard, 1998), but in most of these studies, $T_{1}$ or $T_{2}$ were used to describe the preference of a solid to a certain fluid, where in most experiments, rocks were saturated with a single fluid; either water or oil.

A limitation of these relaxation measurements is that in complex pore systems different fluids cannot be separated from the $T_{1}$ or $T_{2}$ alone since the water signal may overlap with the oil signal when confined in small pore spaces. In such cases, the strength of the interaction of the fluid with the solid shortens the transverse from the longitudinal relaxation of the fluid that is in closer contact to the solid. The $T_{2}$-shortening is reflected in the $T_{1} / T_{2}$ ratio, and a high ratio is the result of the fluid adsorbing on the surface. The ratio of relaxation times $T_{1} / T_{2}$ is independent of pore geometry and is only affected by changes in the surface relaxivity. It has consequently been used describe the chemical exchange between water and cement paste (McDonald et al., 2005), while, D’Agostino et al., (2014) studied the $T_{1} / T_{2}$ ratio in order to define the adsorption strength of water on different catalysts.

In a geological context, Kleinberg et al., (1993), used the $T_{1} / T_{2}$ ratio to illustrate the shortening of the transverse relaxation due to magnetic field gradients, They concluded that when sufficiently small echo spacing is used, the shortening of $T_{2}$ at 1 to $2 \mathrm{MHz}$ Larmor frequency can be minimized, and that the $T_{2}$ distribution has a similar appearance to $T_{1}$ with a slight shift of the scale, which due to microscopic field gradients cannot be eliminated.

The present study discusses a new method based on data acquired from low field NMR spectrometry for determining wettability in partially saturated reservoir rocks. It has potential applications to wettability interpretation at in-situ conditions from measurements made downhole by a NMR logging tool. We present $T_{1} / T_{2}$ ratio based wettability calculations in complex systems; including a rock with 
bimodal pore size distribution containing both oil and water. Our calculations require two sets of $T_{1}$ and $T_{2}$ measurements: (1) at $100 \%$ saturation with a wetting fluid and (2) at partial saturation with a wetting or a non-wetting fluid.

\section{Rock material and brines}

The selected reservoir chalk is from Tor Formation of the Gorm field in the North Sea (Bæk, 2014). For the case of argillaceous sandstones we studied two different types; sandstone from Berea and reservoir greensand from the Solsort field in the North Sea (Bæk, 2014).

The rock samples comprise three plugs of chalk, three plugs of Berea sandstone and three plugs of greensand. Core plugs were cleaned using the Soxhlet extraction technique and dried at $60^{\circ} \mathrm{C}$ for 3 days. All samples are vertical and have the same size (37 mm diameter and $30 \mathrm{~mm}$ length). The plugs are divided into batches of three. Each batch comprises one plug of chalk, one greensand and one Berea sandstone.

The first batch of core plugs was saturated only with salt water, the second batch only with dead oil and the third batch with dead oil and salt water at irreducible water saturation. The salt water was chosen to be $30000 \mathrm{ppm} \mathrm{NaCl}$ solution and the selected dead oil came from the South Arne field, Danish North Sea (Bæk, 2014) (Table 1). The density of the salt water $\left(1.019 \mathrm{~g} / \mathrm{cm}^{3}\right)$ and of dead oil $\left(0.845 \mathrm{~g} / \mathrm{cm}^{3}\right)$ was measured using a digital density meter of high accuracy $( \pm 0.001)$.

\section{Methods}

Characterization. The specific surface area $\left(S_{B E T}\right)$ of the samples with respect to weight $\left(\mathrm{m}^{2} / \mathrm{g}\right)$ was obtained with the nitrogen adsorption method using the Autosorb iQ gas sorption system from Quantachrome Instruments. Helium porosity and Klinkenberg corrected permeability were measured on cleaned and dried core plugs using a PoroPerm Production 2 gas porosimeter from Vinci Technologies. Table 1 summarizes all the results.

Table 1 Rock properties.

\begin{tabular}{ccccccc}
\hline Sample ID & Lithology & $\begin{array}{c}\text { Helium } \\
\text { Porosity } \\
\text { (fraction) }\end{array}$ & $\begin{array}{c}\text { Klinkenberg } \\
\text { permeability } \\
(\mathrm{mD})\end{array}$ & $\begin{array}{c}\mathrm{S}_{\mathrm{BET}} \\
\left(\mathrm{m}^{2} / \mathrm{g}\right)\end{array}$ & $\begin{array}{c}\text { Water } \\
\text { saturation, } \\
\%\end{array}$ & $\begin{array}{c}\text { Oil } \\
\text { saturation, } \\
\%\end{array}$ \\
\hline N-3X-T1 & Gorm field & 0.35 & 4.16 & 1.4 & 100 & 0 \\
N-3X-T2 & Chalk & 0.35 & 4.16 & 1.4 & 0 & 98 \\
N-3X-T3 & 0.34 & 6.07 & 1.2 & 40 & 60 \\
\hline BS-T1 & Berrea & 0.20 & 99.7 & 1.3 & 96 & 0 \\
BS-T2 & Sandstone & 0.20 & 85.4 & 1.3 & 0 & 97 \\
BS-T3 & 0.22 & 196.5 & 1.2 & 17 & 83 \\
\hline GSD-T1 & Solsort & 0.32 & 117.6 & 8.7 & 100 & 0 \\
GSD-T2 & field & 0.32 & 116.1 & 8.7 & 0 & 100 \\
GSD-T3 & Greensand & 0.32 & 111.4 & 8.7 & 46 & 54 \\
\hline
\end{tabular}

NMR measurements. NMR measurements were made at a 2 MHz Magritek Rock Core Analyzer ${ }^{\mathrm{TM}}$ at $40^{\circ} \mathrm{C} \cdot T_{1}-T_{2}$ maps were constructed using similar acquisition parameters as in $T_{2}$ measurements for the transverse relaxation time (Sun et al., 2004). $T_{2}$ relaxations were measured using the CPMG pulse sequence (Dunn et al., 2002) at Signal to Noise Ratio (SNR) equal to 250. The polarization time was selected at $5 \mathrm{~s}$, number of echoes at 16000 , and the echo spacing (TE) at $100 \mu \mathrm{s}$. The raw 2D data were analyzed using a two dimensional distribution function and an inverse Laplace transform to generate the 2D maps (Hürlimann et al., 2003).

\section{Results and discussion}


Figure 1 presents the $T_{1}-T_{2}$ maps. We divided each $T_{1}-T_{2}$ map in two regions; one for relaxation times lower than $50 \mathrm{~ms}$ and the other one for higher values. For each region, the $T_{1} / T_{2}$ ratio was calculated at the point of highest intensity in the map (light yellow colour). Table 2 summarizes all the results.
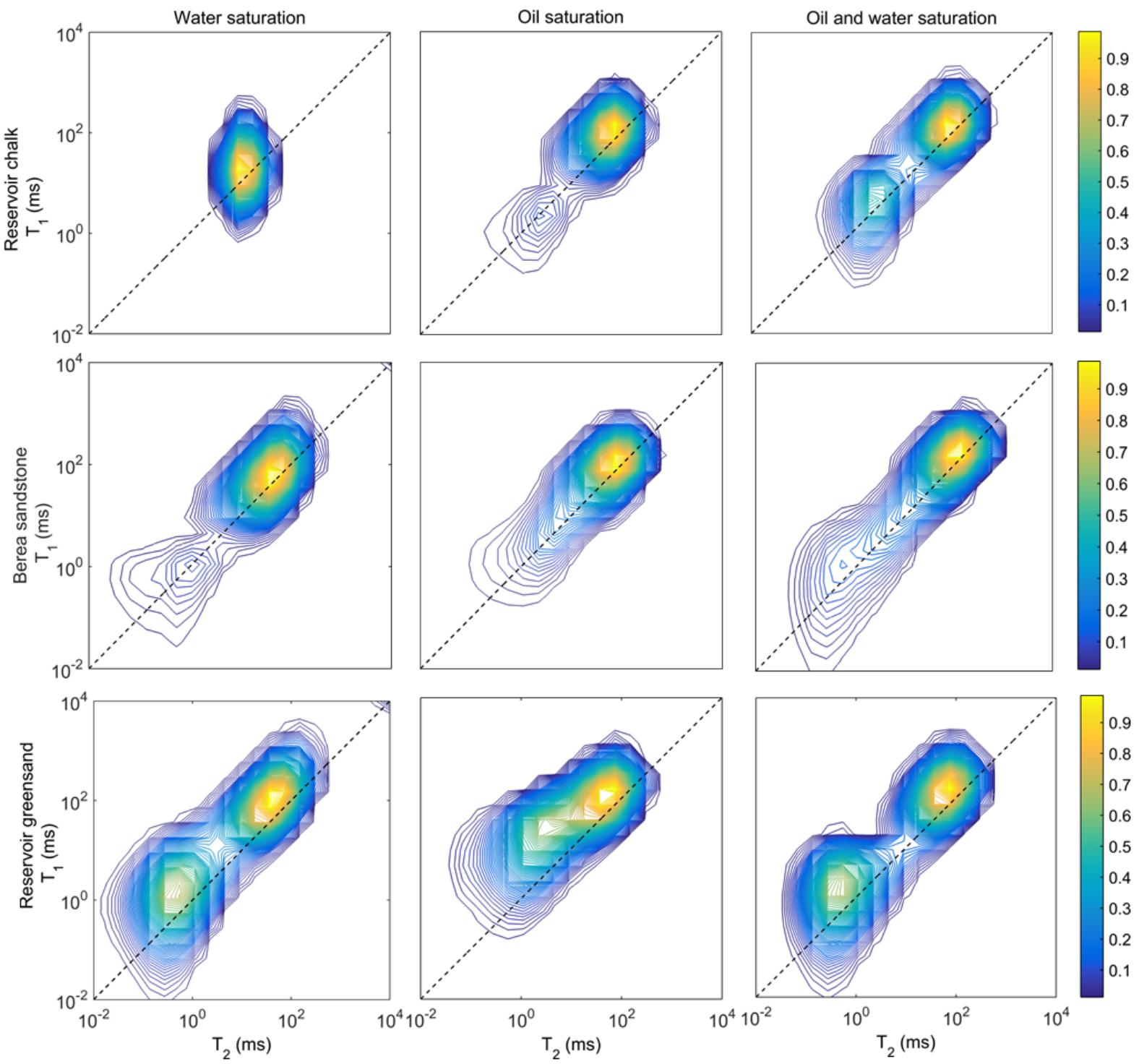

Figure $1 T_{1}-T_{2}$ maps of reservoir chalk, Berea sandstone and reservoir greensand. The first column represents rocks saturated with water, the second column rocks saturated with oil and the third one rocks saturated with oil and water at irreducible water saturation.

In the case of chalk, the $T_{1} / T_{2}$ ratio is higher when there is water instead of oil present in the pore space. In the case of both oil and water saturated chalk, the left peak has higher $T_{1} / T_{2}$, representing the strong attraction of the water to the surface. The $T_{1} / T_{2}$ ratio is higher when water comes in contact with the surface of the mineral than when oil wets the surface. The increase in the ratio indicates the strong water-chalk affinity. In the case of Berea sandstone the $T_{1} / T_{2}$ ratio is similar in both regions when there is either water or oil present in the pore space. In the case of both oil and water saturated rock, the first peak has relatively higher $T_{1} / T_{2}$; but the negligible differences could be interpreted as a neutral response to both water and oil. In the case of greensand the $T_{1} / T_{2}$ ratio of the fast relaxing components (small pores) is higher when there is oil instead of water present in the pore space. On the other hand, the slow relaxing components (big pores) have a higher ratio when in contact with water than with oil. Of the two minerals that dominate the mineralogy of greensand, chlorite occupies 
the small pores and shows high oil attraction compared to quartz. This could be an indication of the mixed wettability of the rock.

Table 2 The $T_{1} / T_{2}$ ratio of the rocks from the $T_{1}-T_{2}$ maps at Figure 1.

\begin{tabular}{|c|c|c|c|c|}
\hline Sample & Lithology & Saturation & $\begin{array}{c}\mathrm{T}_{1,2}<50 \mathrm{~ms} \\
\mathrm{~T}_{1} / \mathrm{T}_{2}\end{array}$ & $\begin{array}{c}\mathrm{T}_{1,2}>50 \mathrm{~ms} \\
\mathrm{~T}_{1} / \mathrm{T}_{2}\end{array}$ \\
\hline N-3X-T1 & \multirow{3}{*}{ Chalk } & Water & - & 2.0 \\
\hline N-3X-T2 & & Oil & 1.0 & 1.2 \\
\hline N-3X-T3 & & Oil and water & 2.3 & 1.4 \\
\hline BS-T1 & \multirow{3}{*}{$\begin{array}{c}\text { Berea } \\
\text { sandstone }\end{array}$} & Water & - & 1.2 \\
\hline BS-T2 & & Oil & 1.1 & 1.1 \\
\hline BS-T3 & & Oil and water & 1.4 & 1.1 \\
\hline GSD-T1 & \multirow{3}{*}{ Greensand } & Water & 2.0 & 2.2 \\
\hline GSD-T2 & & Oil & 3.8 & 1.2 \\
\hline GSD-T3 & & Oil and water & 1.9 & 1.6 \\
\hline
\end{tabular}

\section{Conclusions}

Low field NMR measurements were done on reservoir chalk, Berea sandstone and chloritic greensand at three different saturation states; water, oil as well as oil and water at irreducible water saturation. The $T_{1} / T_{2}$ ratio was used as a mechanism to quantify the fluid-solid affinity in reservoir rocks. The $T_{1} / T_{2}$ ratio illustrates the strength with which a fluid adsorbs on a solid; the higher the adsorption strength the higher the ratio. The fluid wetting the surface of a mineral has higher ratio than other fluids present in the pore space.

\section{Acknowledgements}

The authors wish to thank the Danish Energy Agency, Mærsk Oil and DONG Energy for funding the research.

\section{References}

Bæk, M., 2014, Oil and Gas Production in Denmark and Subsoil Use, Danish Energy Agency, ISBN: www-978-87-93071-71-1, ISSN: 1904-0253.

D'Agostino, C., Mitchell, J., Mantle, Michael D., and Gladden, L.F., 2014, Interpretation of NMR Relaxation as a Tool for Characterising the Adsorption Strength of Liquids inside Porous Materials, Chemistry European Journal, 20(40), 13009-13015.

Dunn, K., Bergman, D.J. and LaTorraca, G.A., 2002, Nuclear Magnetic Resonance-Petrophysical and Logging Application, New York, Handbook of Geophysical Exploration, Pergamon Press.

Freedman, R., Heaton, N., Flaum, M., Hirasaki, G. J., Flaum, C., and Hürlimann, M. D., 2003, Wettability, saturation, and viscosity using NMR measurements: SPE Journal, 8(12), 317-324.

Hürlimann, M. D., Freedman, R., Venkataramanan, L., Flaum, C., Flaum, M., Hirasaki, G. J., 2003, Diffusion-relaxation distribution functions of sedimentary rocks in different saturation states, Magnetic Resonance Imaging, 21(3-4), 305-310.

Hsu, W., Li, X., and Flumerfelt, R.W., 1992, Wettability of Porous Media by NMR Relaxation Methods. Washington, DC, SPE24761.

Howard, J., 1998, Quantitative estimates of porous media wettability from proton NMR measurements, Magnetic Resonance Imaging, 16(5), 529-533.

Kleinberg, R.L., Farooqui, S.A., and Horsfield, M.A., 1993, $\mathrm{T}_{1} / \mathrm{T}_{2}$ Ratio and Frequency Dependence of NMR Relaxation in Porous Sedimentary Rocks, Colloid Interface Science, 158, 195-198.

McDonald, P.J., Korb, J.-P., Mitchell, J. and Monteilhet L., 2005, Surface relaxation and chemical exchange in hydrating cement pastes: A two-dimensional NMR relaxation study, Physics Review, E 72, 011409. 